\title{
Tribological Behavior and Analysis on Surface Roughness of CNC Milled Dual Heat Treated Al6061 Composites
}

\author{
A. Bovas Herbert Bejaxhin, ${ }^{1}$ G.M. Balamurugan, ${ }^{2}$ S.M. Sivagami, ${ }^{3}$ K. Ramkumar, ${ }^{4}$ \\ V. Vijayan $\mathbb{D}^{5},{ }^{5}$ and S. Rajkumar $\mathbb{D}^{6}$ \\ ${ }^{1}$ Department of Mechanical Engineering, Saveetha School of Engineering, SIMATS, Chennai, Tamil Nadu, India \\ ${ }^{2}$ Department of Mechanical Engineering, Solamalai College of Engineering, Veerapanjan, Madurai-625020, Tamil Nadu, India \\ ${ }^{3}$ Department of Mechanical Engineering, Alagappa Chettiar Government College of Engineering and Technology, Karaikudi, \\ Tamil Nadu, India \\ ${ }^{4}$ Department of Mechanical Engineering, Dhanalakshmi Srinivasan Institute of Technology, Samayapuram, Trichy 621112, \\ Tamil Nadu, India \\ ${ }^{5}$ Department of Mechanical Engineering, K.Ramakrishnan College of Technology, Samayapuram, Trichy 621112, \\ Tamil Nadu, India \\ ${ }^{6}$ Department of Mechanical Engineering Faculty of Manufacturing Institute of Technology, Hawassa University, Ethiopia
}

Correspondence should be addressed to S. Rajkumar; rajkumar@hu.edu.et

Received 7 October 2021; Revised 3 November 2021; Accepted 13 November 2021; Published 27 November 2021

Academic Editor: Fuat Kara

Copyright (c) 2021 A. Bovas Herbert Bejaxhin et al. This is an open access article distributed under the Creative Commons Attribution License, which permits unrestricted use, distribution, and reproduction in any medium, provided the original work is properly cited.

Dual heat treatment (DHT) effect is analyzed using the machining of Al6061-T6 alloy, a readily available material for quickly finding the machining properties. The heat treatments are conducted twice over the specimen by the furnace heating before processing through CNC machining. The HSS and WC milling cutters are preferred for the diameter of $10 \mathrm{~mm}$ for the reviewed rotational speeds of $2000 \mathrm{rpm}$ and $4000 \mathrm{rpm}$, and the constant depth of cut of $0.5 \mathrm{~mm}$ is chosen based on various reviews. Worthy roughness could be provided mostly by the influence of feed rates preferred here as $0.05 \mathrm{~mm} / \mathrm{rev}$ and $0.1 \mathrm{~mm} / \mathrm{rev}$. The influencing factors are identified by the Taguchi, genetic algorithm (GA), and Artificial Neural Network (ANN) techniques and compared within it. The simulation finding also helps to clarify the relationship between influenced machining constraints and roughness outcomes of this project. The average values of heat treated and nonheat treated Al6061-T6 are compared and it is to be evaluated that $41 \%$ improvement is obtained with the lower surface roughness of $1.78975 \mu \mathrm{m}$ and it shows good surface finish with the help of dual heat treatment process.

\section{Introduction}

By the identification of influencing factors on any machining outcomes this will be very useful by its interpreted data for the product improvement in the factory floor. Improvement of surface perfections and the tool life is an admirable task by utilizing the proper machining conditions and the work environment. The various methods have been implemented to improve the surface roughness and tool life. The heat treatment is a process of modulating or changing the material characterization and microconstitutions too. The dual heat treatment can be used here for evaluating the better surface finish used among the suitable tool material types. The differentiation of tools can be analyzed here with the effect of dual heat treatment on each specimen. Paper [1] evaluated that the surface roughness has reduced by the percentage confidence level and relatively $8 \%$ of improvement has been obtained in its roughness by the dominance of cutting speed as machining parameter. Houchuan et al. (2015) have discussed the surface roughness improvement that was good during the machining with lower and higher cutting speeds. Microvoids of scratches and burr formation 
have been identified from the microstructures of tearing surface. Paper [2] has discussed the tool wear and surface roughness of steel specimen machined with coated inserts with the involvement of austenitizing and tempering heat treatments. The hardness becomes more due to lowering the tempering temperature. Thermally heat treated steel specimen with coated carbide inserts have proven effective wear mechanism with the improved tool life. The discussion is about the closeness of the predicted values of particle swarm optimization (PSO) technique which exactly coincide with the experimental roughness values. It can be observed that the roughness becomes poor due to the factors of higher cutting speed. The lesser value of feed rate can boost up the surface quality [3]. İrfan Ucun et al. [4] have conducted the finite element simulation for various chip formation related with the surface roughness of machined areas.

V. Arumugaprabu et al. [5] have analyzed the effect of cutting forces impact on surface texturing for developing the new type of surface texture pattern. Here they mentioned that it reduced the wear rate and also improved the performance of the cutting tool. Paper [6] has discussed the simulation procedures of Deform 3D for the high speed milling process with different machining and process parameters. This has been conducted with different geometrical changes in tool edge radius and heating effects. The laser assisted milling does not influence the specimen characteristics or properties and that was limited to a shallow layer on the peripheral of the work piece that was machined by LAML [7]. Paper [8] has discussed that the total elastic deformation can be calculated in face milling operation which can be identified through the tool flank wear as the major root cause of increasing the elastic deformation. This will lead to poor finishing in the surface levels of milling. The removal of chips during metal cutting has been simulated with the help of Deform 3D tool used to verify the effective stress, strain, and displacement. They also discussed that the major influencing factor on chip removal and the consistent flow of machining have been verified by Dyi-Cheng Chen et al. (2016). Paper [9] discussed the three stages of heat treatment which define the annealing process to make the materials very strong. Here the fine martensite can be entrenched within the ferrite grains observed from the microstructure. Simultaneously the hardness can be improved based on the percentage of carbon and the annealing temperatures. It has been discussed that the martensite structure changes which was identified through SEM images. The reduction of cutting forces with the increase in cutting speed leads to lowest surface roughness observed by Xu Chuangwen et al. [10]. The changes in dual phase stages of annealing heat treatment for various temperatures on steel specimen can be verified by the influencing parameters evaluated based on the increasing volume fraction of martensite in dual phase steel. It can be evaluated that the surface roughness has reduced by the percentage confidence level and there was relatively $8 \%$ improvement obtained in its roughness by the dominance of cutting speed as machining parameter [1]. The measurement of roughness has been carried out here with the minimum range $0.43 \mu \mathrm{m}$. It has been discussed that the minimum error percentage has occurred for the successful roughness values [11]. Paper [12] has discussed that the increase in cutting speed leads to decreasing the average surface roughness of milling specimen as wood and the increase of average roughness with the increase of feed rate and speed. There was no improvement made on wood due to thermal treatment. The geometrical parameters of the tool and its radius and the misalignments of the teeth have taken part for improving the machining surface quality as has been discussed. In particular, the better profile of tool selection is an important outcome observed here by Benattia Bloul et al. [13]. Paper [14] has discussed the laser metal deposition method of additive manufacturing in milling surface in top and side of the Ti-6Al-4V specimen. The metal cutting can be carried out with the lubrication of dry, cryogenic, and coolants process. The surface quality can be measured on side and top side of various samples corresponding to various cutting conditions. They proved that, based on fluorescence analysis results, the cryogenic treatment process can achieve good surface finish and better tool life because of defect-free surface compared with dry machining and coolant usage. Paper [15] has discussed that the machinability of Ti-6Al-4V titanium alloy can be better with the heat treatment process using PCD tools. The authors have evaluated that the air cooled specimen attained higher hardness with the ascription of homogeneous lamellar $\alpha+\beta$ Ti-6Al-4V microstructure with the absence of $\alpha^{\prime}$ secondary precipitate which helped for the improved performance Paper [16] has discussed the performance over the tool life and the reduction of cutting forces by using cryogenic cooling lubricants on $\mathrm{H} 13$ steel. The evidently proved that the milling cutter with double straight channel (DSC) with minimum quantity lubrication technique is combined and performed well on tool life economically. Paper [17] has discussed the temperature distribution in the cutting zone during raster milling operation for the specified cutting conditions. They evaluated that the increase of spindle speed and feed rate produced more heat in the machining. The decreasing of depth of cut used to decrease heat first and then it can increase the cutting temperature on the milled Al6061 alloy. Paper [18] has discussed the consequence of tool coatings and holder coating in CNC milling influenced by surface roughness with some optimized outcomes verified with the experimental results. The dynamic simulation can also be verified with the experimental output parameters which represent that the perfection of roughness is based on the coated effects in the tool and holder assembly. Paper [19] has discussed the surface roughness improvement that was good during the machining with lower and higher cutting speeds. Microvoids of scratches and burr formation have been identified from the microstructures of tearing surface. Paper [20] has discussed the importance of coatings and then proved that the surface improvement can be accomplished by the milling cutter coated with nanosized diamond grains. The tool life can be improved four times more than the uncoated milling cutters.

Reference [21] has discussed the energy efficient cutting parameters that can be utilized for cutting tool development, even chip formation, and better tribological properties in metal cutting. They have found that the higher cutting speed 
and the range of feed rates are the most influencing parameters on Specific Consumption of Energy (SCE). Reference [22] has demonstrated that single phase Al rich alloys containing 5-15 percent $\mathrm{Zn}$ increase hardness and tensile strength. As the zinc concentration grew, so did the surface roughness development and chip size during alloy machining. Paper [23] has discussed that the increase of cutting speed beyond the maximum limit can reveal the irrelevant chip serration in its morphology. In [24] material removal in nitrogen sprayed samples happens as a result of interparticle boundary failure in both the as-made and annealed states, whereas material removal in helium sprayed samples can include a mix of chip formation and interparticle boundary failure. The ductility and strength of the interparticle boundaries are improved by annealing the helium sprayed material, resulting in solely chip formation and an improvement in the machined surface. Reference [25] has discussed, in milling procedures, the influence of varying radial depth of cut on cutting force values. In addition, it was suggested that future studies include a comparison of experiment outcomes with simulation results. It has been proved that using the right optimization method can cut machining time in half.

In this research article, the surface quality can be measured over the heat treated and nonheat treated specimens based on the influencing machining parameters and simulated predictions. The optimized outcome also plays an important role of finding the optimal solution of surface roughness. The effective stress variation and deflections should reach the satisfied level with the comparison of experimental results through this machining process.

\section{Experimental Procedure}

2.1. Materials and Methods. Most industries should be aware of the necessity of heat treatment methods based on their demands and requirements. This type of dual treatment method of heating can be used to improve the grain structure and hardness of any ferrous or nonferrous material. These approaches can aid in the identification of superior material qualities during the raw material selection process. The Aluminium 6061-T6 alloy was preferred for the specimen material. It is of relatively less weight but more strength, readily available, and suitable for any type of metal forming, shaping, and machining. Al6062-T6 is present under the standard of $\mathrm{H} 20$ with the grade of 65032/Al6061.

It contains up to $0.8 \%$ silicon and $1.2 \%$ magnesium as alloying element as shown in Table 1 which is used to strengthen its microconstituents and improve the hardness without affecting the ductility. The titanium and chromium inclusion helps to get very strong in tensile strength and more toughness. The consolidated effect of these entire allying elements present in this Al6061-T6 is the key factor for selecting this as work material. Based on the material selection and the valuable previous research reviews, we can prefer the machining conditions for this milling operation as mentioned in Table 2.

Heat treatments can be defined as an operation or combined form of operations which involves heating and cooling of a metal or alloy in a solid region to accomplish the desired properties. The heat treatments can be used to change the material properties very conveniently for a specific application. It is a modifying operation which is used for the manufacturing process of any machine parts or cutting tools. It is used to relieve internal stresses, soften the material, and improve hardness and machinability. The simple heat treatments can be applied for nonferrous materials like aluminium and titanium which is used to improve the mechanical properties.

In general the tempering heat treatment process can be used for the specimen used here before the milling starts. In the primary heat treatment stage, each specimen can be involved in the tempering heat treatment process at the temperature range of $1500 \mathrm{C}-2000 \mathrm{C}$ by using muffle furnace KSM-0012 as shown in Figure 1. After quenching the specimen when it has been extracted out from the furnace, in the secondary heat treatment process the tempering temperature can be increased to $2500 \mathrm{C}$. Now this time the specimen becomes air-hardened naturally at the open surface after the completion of secondary heat treatment. This is referred to as dual heat treatment method. For the completion of every heat treatment process, the specimen can be hot-pressed by the FIE-Universal 2001 (UTE) universal testing compression section for the compressive load of $400 \mathrm{KN}$. Hence the specimen will get very strong in its grain size and hardness.

Most industries should be aware of the necessity of heat treatment methods based on their demands and requirements. This type of dual treatment method of heating can be used to improve the grain structure and hardness of any ferrous or nonferrous material. These approaches can aid in the identification of superior material qualities during the raw material selection process.

2.2. CNC Machining and Roughness Measurement. The milling operation is planned with the machining conditions as mentioned in Table 2, and the work has been performed in the CNC milling machine named as AMS Acer Micrometric as shown in Figure 2, which has more precise and dynamic cutting conditions with fast and furious tool changer mechanisms. The required High Speed Steel (HSS) end milling cutter of $10 \mathrm{~mm}$ in diameter can be used for the machining operation and the carbide milling cutter also affixed with the tool changers.

Separate programming can be done for the required slot milling operation. Each slot can be machined up to $40 \mathrm{~mm}$ in length and $10 \mathrm{~mm}$ in width where we already know that the end milling diameter is $10 \mathrm{~mm}$. After the fixation of work material in the milling table with suitable fixture and jigs for the rigid support as shown in Figure 2, as planned earlier with the reciprocation of the machining conditions, the heat treated and nonheat treated Al6061 specimens can be involved for the milling operation by using the HSS and carbide milling cutters, the fine removal of material from the specimen exterior surface, and the lower feed rate applied which is used to produce the good surface roughness among work material. The Aluminium 6061 alloy specimen was 
TABle 1: Al6061-T6 alloy chemical composition.

\begin{tabular}{lcccccccccc}
\hline Material & $\mathrm{Al}$ & $\mathrm{Cr}$ & $\mathrm{Cu}$ & $\mathrm{Fe}$ & $\mathrm{Mg}$ & $\mathrm{Mn}$ & $\mathrm{Si}$ & $\mathrm{Ti}$ & $\mathrm{Zn}$ & $\mathrm{Others}$ \\
\hline $\mathbf{\%}$ & $95.8-98.6$ & $0.04-0.35$ & $0.15-0.4$ & $\mathrm{Max} 0.7$ & $0.8-1.2$ & 0.15 & $0.4-0.8$ & 0.15 & 0.25 & 0.20 \\
\hline
\end{tabular}

TABLE 2: Machining conditions.

\begin{tabular}{lc}
\hline & Input parameters:- \\
\hline Specimen material & Al6061-T6 alloy (HT, non-HT) \\
Tool material & High Speed Steel (HSS) (Ø10 mm) \\
Speed (N) & Tungsten carbide end milling cutters (Ø10 mm) \\
Feed rate (f) & $2000 \mathrm{rpm}, 4000 \mathrm{rpm}$ \\
Depth of cut (d) & $0.05 \mathrm{~mm} / \mathrm{rev}, 0.1 \mathrm{~mm} / \mathrm{rev}$ \\
Output responses & $0.5 \mathrm{~mm}(\mathrm{constant})$ \\
& Influencing factors (optimization) \\
\end{tabular}

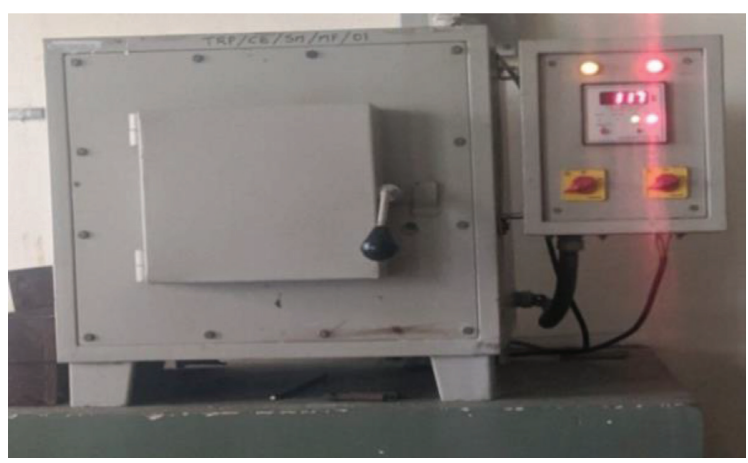

Figure 1: Heat treatment by muffle furnace KSM-0012.

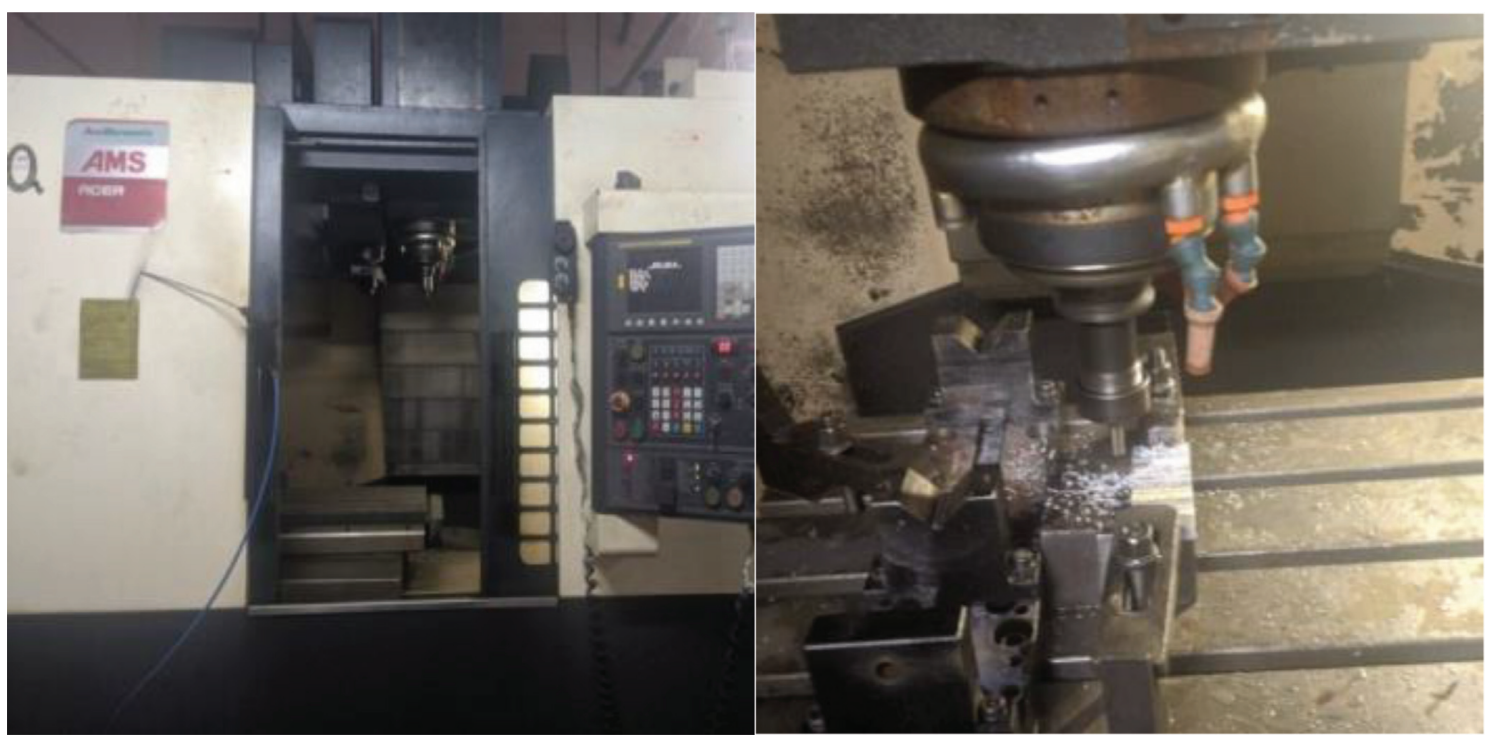

FIGURE 2: Experimental setup in CNC milling machine.

chosen for the size of $100 \mathrm{~mm} \times 40 \mathrm{~mm}$ for the thickness of $10 \mathrm{~mm}$ for the milling operation. The end milling cutter was used here with the diameter of $10 \mathrm{~mm}$. The length of chipped area is comprised of $40 \mathrm{~mm}$ length and $10 \mathrm{~mm}$ width and the few grams of fine particulate metal dust were deposited during the machining.
The cutting edges of HSS milling cutters and tungsten carbide end milling cutters are used to remove the work material from the specimen surface with the specified rotational speeds and constant depth of cut of $0.5 \mathrm{~mm}$. For this CNC milling operation, water-based semisynthetic oil "MOBILCUT-80" Trading CNC Machine Coolant Oil was 
utilized. During high temperature interactive machining, it has a better viscosity and lubrication. Heat is minimized and evacuated from the cutting zone and the work piece. By reducing friction, it lubricates the instrument and aids in chip removal. Chips and abrasive particles are washed out of the work area. It protects against corrosion. In addition, the continuous effect of cooling can be done over the machining centre by the semisynthetic or soluble oil as coolant in view of minimizing the heat affected zone during milling process. The surface imperfections can be measured with the highly precise diamond probe of Mitutoyo surface roughness tester as shown in Figure 3(a).

\section{Results and Discussion}

3.1. Comparison of Roughness Findings. The essential outcomes will be reproduced into useful data for the product development in the factory applications. The surface quality can be drastically improved by the involvement of heat treated specimen in the CNC milling operation. In addition, the dual heat treatment process (DHT) can be incorporated for the additional improvements in surface roughness which has been proved from these research outcomes.

Kahraman and Sagbas [6] have concluded that the heat treatment had decreased the surface roughness values and it was evaluated from the influencing factors of heat treatment on the surface roughness which makes the difference of nonheat treated and heat treated specimen by the performance of one-way ANOVA test. Based on these kinds of previous research reviews and the confirmation of the experimental readings of the present research which is shown in Table 3, the present work represents the surface roughness recorded in each slot which has been machined with two different end milling cutters. In particular, the HSS end milling cutters cannot provide sufficient outcome in the surface quality improvement. Here the changes of feed rate and the rotational speeds can be varying with some observations of surface roughness. The variation of hardness levels has been shown in Table 3 due to the dual heat treatment effect. It was observed that the increase of hardness was obtained in both Brinell and Rockwell hardness values due to the heat treatment effect. As we know from different conclusions from various research articles, the feed rate can be considered as a secondary root cause of surface perfections. Here from these observations, somewhat better surface roughness was obtained due to the lower rotational speed of $2500 \mathrm{rpm}$ for both the feed rates. During the experimental outcomes, the $41 \%$ improvements in surface roughness have been obtained by the effect of heat treatment as well as the specific machining conditions. In this case, the machining conditions have a significant impact on surface roughness. Most characteristics, such as feed rate and speed, have a significant impact on surface roughness. At the same time, the material property is an extra feature that can be used to characterize the roughness of a specimen or a cutting tool. Based on the machining circumstances, the HSS and carbide milling cutters performed exceptionally well in this experiment. However, as compared to HSS end milling cutters, the carbide end milling cutter, which has better rigidity and toughness with lower wear rates, fared well in terms of surface roughness. The applied speed and feed rate can also influence the roughness decrease or increase.

The influencing factors can be identified from the response of the means and signal to noise ratio as shown in Table 4 from Taguchi analysis of optimization procedures. It was clearly represented that the cutting tool and the workpiece which are ranked as 1 and 2 are the majorly influencing factors on surface roughness which have been considered as primary and secondary dominant factors. This would be explained by the fact that the effect of integral changes on each specimen can occur in either its microstructure or hardness due to this dual heat treatment process.

\subsection{Influencing Parameters by Optimization Procedure.}

The Taguchi orthogonal array technique L8 was designed for the 4 factors of 2 level designs and the analysis of variance (ANOVA) was performed for finding the effect of parameters on the response variables in Minitab 17. The interaction plots and the main effects plots of means can clearly explain that the lower values of roughness can be indicated more with the parameters of workpiece and cutting tools with huge deviations even as the other parameters have not significantly affected the response. The deviations in their observations can be varied with respect to various parameters. So it can be confirmed that certain parameters could be considered as influencing factors based on Figure 4.

In order to determine the influence of each parameter on the surface roughness ANOVA was employed. The results of the ANOVA are presented in Table 5. Based on the contribution percentage of the predictive model and that of the experimental results, the model was found to be adequate. The experimental and predicted values of regression model are depicted in Figure 5. It is obvious from Figure 5 that there is a close agreement between experimental values and that of the predicted values. Even in the regression analysis it was carried out for the significance level of 0.1 which was referred to as the confidence level of $90 \%$ and with the basis of a $P$ value less than 0.1 which is considered to have statistically considerable contribution to the performance measures.

It was found that the optimum process parameters are identified as workpiece of Al6061 heat treated, carbide tool type, speed of $2500 \mathrm{rpm}$, and the feed rate of $0.1 \mathrm{~mm} / \mathrm{rev}$ from Figure 6 . The degree of influence on the results can be showed by the percentage contribution of significant source of the total variation in the last column of Table 4(b). It was found that the tool type has higher contribution to improve the surface roughness. It was concluded based on the calculated contribution percentage. The R-sq and R-sq (adj) values were above the $80 \%$ obtained. The experimental results are good for further prediction. This can be very helpful to the industrial milling projects of better quality surface morphologies. The regression equation can be formed by the genetic linear model of regression analysis given by 


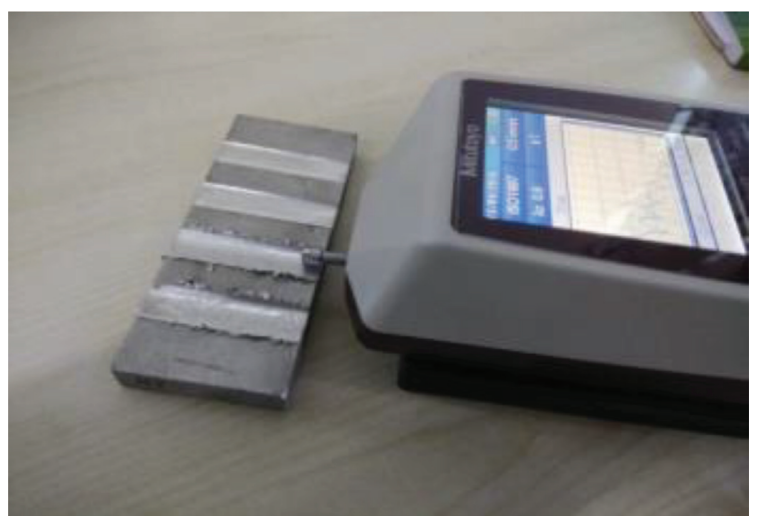

(a)

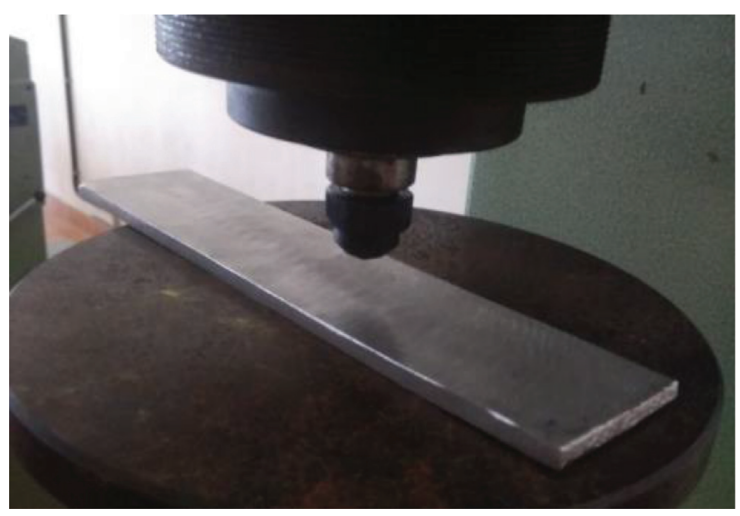

(b)

Figure 3: (a) Measurements of Ra on machined slots with Mitutoyo surface roughness tester. (b) Hardness measurement in the Rockwell hardness setup.

Table 3: Graphical observations of CNC milling outcomes.

\begin{tabular}{|c|c|c|c|c|c|c|}
\hline Specimen & $\begin{array}{c}\text { Hardness (BHN and } \\
\text { RHN) }\end{array}$ & Tool & $\begin{array}{l}\text { Speed (N) } \\
\text { (rpm) }\end{array}$ & $\begin{array}{l}\text { Feed rate }(f) \\
(\mathrm{mm} / \mathrm{rev})\end{array}$ & $\begin{array}{l}\text { Surface roughness } \\
\qquad(\mu \mathrm{m})\end{array}$ & $\begin{array}{l}\text { Average surface } \\
\text { roughness }(\mu \mathrm{m})\end{array}$ \\
\hline \multirow{4}{*}{ Al6061 heat treated } & \multirow{2}{*}{$110.34 \mathrm{BHN}$} & \multirow{2}{*}{ HSS } & 2500 & 0.05 & 2.796 & \multirow{4}{*}{1.78975} \\
\hline & & & 3800 & 0.1 & 3.082 & \\
\hline & \multirow{2}{*}{$66.81 \mathrm{RHN}$} & \multirow{2}{*}{ Carbide } & 2500 & 0.1 & 0.384 & \\
\hline & & & 3800 & 0.05 & 0.897 & \\
\hline \multirow{4}{*}{$\begin{array}{l}\text { Al6061 nonheat } \\
\text { treated }\end{array}$} & \multirow{2}{*}{$101.71 \mathrm{BHN}$} & \multirow{2}{*}{ HSS } & 2500 & 0.1 & 4.807 & \multirow{4}{*}{3.03775} \\
\hline & & & 3800 & 0.05 & 5.354 & \\
\hline & \multirow{2}{*}{$65.825 \mathrm{RHN}$} & \multirow{2}{*}{ Carbide } & 2500 & 0.05 & 1.033 & \\
\hline & & & 3800 & 0.1 & 0.957 & \\
\hline
\end{tabular}

TABLE 4: (a) Response table for means and signal to noise ratios; (b) regression analysis (ANOVA) by genetic linear model on surface roughness $(\mathrm{DF}=$ degree of freedom, $\mathrm{SS}=$ sum of squares, $\mathrm{MS}=$ mean squares, $C=$ contribution $)$.

\begin{tabular}{|c|c|c|c|c|c|c|}
\hline Level & Work piece & Tool & Speed & Feed rate & & \\
\hline 1 & 1.7898 & 4.0098 & 2.2550 & 2.5200 & & \\
\hline 2 & 3.0378 & 0.8177 & 2.5725 & 2.3075 & & \\
\hline Delta & 1.2480 & 3.1920 & 0.3175 & 0.2125 & & \\
\hline Rank & 2 & 1 & 3 & 4 & & \\
\hline Level & Work piece & Tool & Speed & Feed rate & & \\
\hline 1 & -2.362 & -11.730 & -3.634 & -5.711 & & \\
\hline 2 & -7.028 & 2.339 & -5.756 & -3.680 & & \\
\hline Delta & 4.665 & 14.069 & 2.122 & 2.031 & & \\
\hline Rank & 2 & 1 & 3 & 4 & & \\
\hline Source & $\mathrm{DF}$ & SS & MS & $\mathrm{F}$ & $P$ & C (\%) \\
\hline Workpiece & 1 & 3.1150 & 3.1150 & 5.73 & 0.096 & 12.26 \\
\hline Tool & 1 & 20.3777 & 20.3777 & 37.51 & 0.009 & 80.18 \\
\hline Speed & 1 & 0.2016 & 0.2016 & 0.37 & 0.585 & 0.793 \\
\hline Feed rate & 1 & 0.0903 & 0.0903 & 0.17 & 0.711 & 0.355 \\
\hline Error & 3 & 1.6297 & 0.5432 & & & 6.413 \\
\hline Total & 7 & 25.4144 & & & & 100 \\
\hline \multicolumn{7}{|c|}{ Model summary } \\
\hline$S$ & R-sq & R-sq (adj) & R-sq (pred) & & & \\
\hline 0.737051 & $93.59 \%$ & $85.04 \%$ & $54.40 \%$ & & & \\
\hline
\end{tabular}



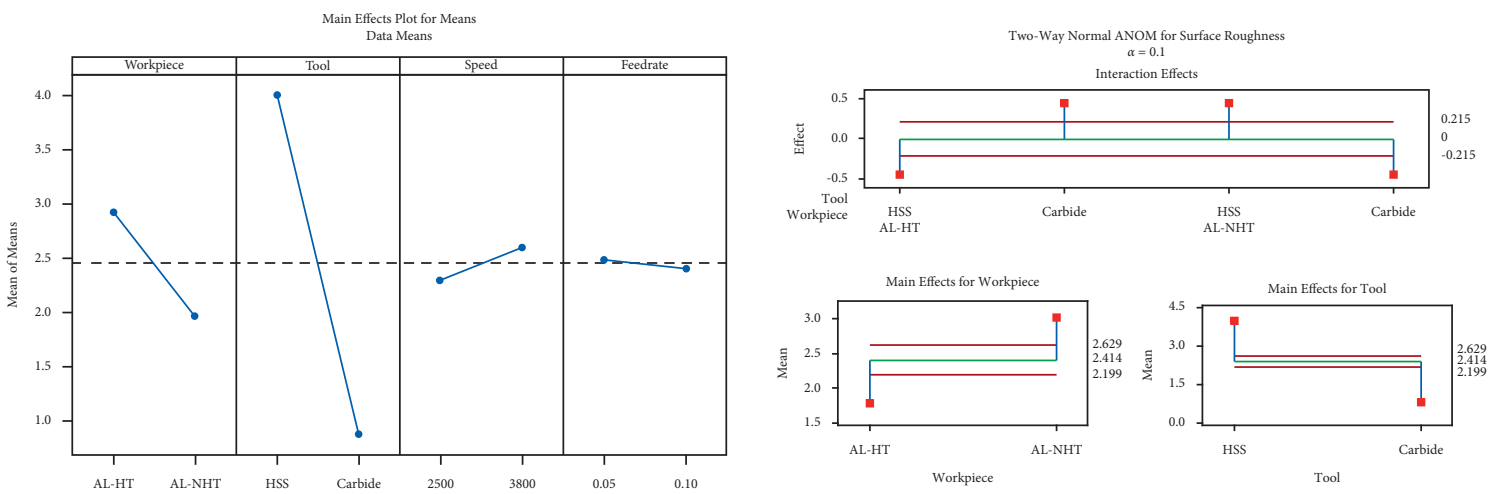

FIGURE 4: Effect of process parameters over the surface roughness by main effects plots and interaction plots for surface roughness.

TABle 5: Percentage of improvement in surface roughness Ra by DHT method.

\begin{tabular}{lcc}
\hline $\mathrm{Al} 6061-\mathrm{T} 6$ heat treated & Al $6061-\mathrm{T} 6$ nonheat treated $(\mu \mathrm{m})$ \\
\hline $1.78975 \mu \mathrm{m}$ & $41 \%$ improved roughness & 3.03775 \\
\hline
\end{tabular}

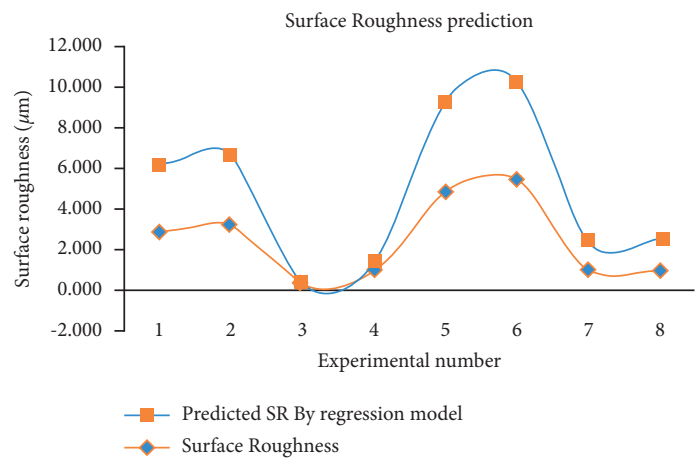

FIgURE 5: Observed deviations between the experimental SR and predicted SR.

Variation of surface roughness $(\mu \mathrm{m})$
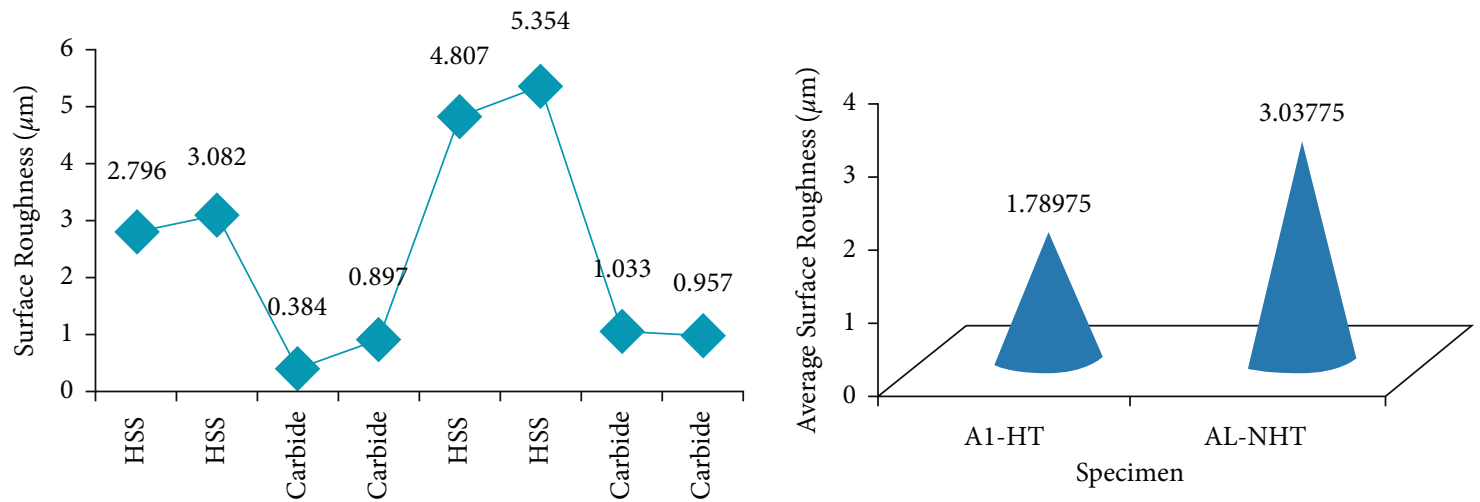

Milling cutter material

FIGURE 6: Variation of surface roughness by the DHT process. 
Sur face Roughness $=2.414-0.624 W 1+0.624 W 2+1.596 T 1-1.596 T 2-0.159$ N1 1 0.159 N2 + 0.106 F1 - 0.106 F2,

where $\mathrm{W} 1, \mathrm{~W} 2$ are specimen, $\mathrm{T} 1, \mathrm{~T} 2$ are cutting tools, $\mathrm{N} 1$, $\mathrm{N} 2$ are rotational speeds $(\mathrm{rpm})$, and $\mathrm{F} 1, \mathrm{~F} 2$ are feed rates $(\mathrm{mm} / \mathrm{rev})$.

3.3. Relative Work Done by GA and ANN. By using the regression equation (1), predicted SR is calculated. In order to verify these optimum process parameters, the genetic algorithm is used. There is one objective in this problem with no constraints. Prior to genetic algorithm calculations, the model adequacy is tested through equation (2) which is given below:

$$
\text { Relative error }(\%)=\frac{\mid \text { Actual value }- \text { Predicted value } \mid}{\text { Actual value }} \text {. }
$$

The predicted outputs and relative error are calculated which are shown below in Table 6 . The following parameters are considered as constant in genetic algorithm (GA): number of variable $=2$, chromosome length $=10$, population size $=100$, crossover probability $=0.7$, mutation probability $=0.1$ single point crossover. Finally, the constant optimum parameters of workpiece of 1 , tool type of 2, and speed of $2478 \mathrm{rpm}$ and feed rate of $0.11 \mathrm{~mm} / \mathrm{min}$ are nearly obtained. It is found that the percentage of relative error is greater than $10 \%$ and it is unacceptable value based on the relative error percentage. In the training parameters of ANN model, number of neurons on the layer input, hidden, and output is 1,2 , and 1 . The initial weight and biases are -1 to 1 , the activation function followed is Tansig with the learning rate of 0.05 , the momentum constant is 0.95 , and the learning technique of backpropagation algorithm is followed.

From the ANN predicted outcomes as shown in Figure 7, this model can easily predict the surface coarseness more accurately compared with the regression model. Less values of relative error have been identified for the predicted SR values by ANN compared with the values of regression model from Table 6. It has mentioned that the type of tool usage was identified the most influencing parameter on surface roughness. The ANOVA results confirmed that the regression model is very adequate and is capable of predicting the SR values.

3.4. Details of Predicted Simulation Outcomes. The prediction through the simulation platform Deform 3D has mentioned more obvious results of stresses and displacements as mentioned in Table 7 which is related to the surface roughness improvement. The predicted values of effective stress and displacement are shown in the graphical representation in Figures 8 and 9. Among the readings observed, the minimum ranges of stresses and displacement have been achieved by the usage of tungsten carbide (WC) milling cutter for both the rotational speeds of $2500 \mathrm{rpm}$ and
$3800 \mathrm{rpm}$. For each machining condition and its consecutive steps, the various effective stress and the displacement values have been mentioned in Table 7 . There are no sufficient improvements marked from the remaining machining conditions.

The interrelation between the feed rate and rotational speed over the surface integrity smoothness can be shown in Figures 10(a) and 10(b). Here the curvilinear color lines differentiate the influence of feed rate and rotational speeds over the surface roughness on each experimental step. The simulation results of stresses and strains have been indicated for various rotational speeds (2500 rpm and $3800 \mathrm{rpm}$ ) and the type of tools (HSS and WC) with diverse heat treatment condition is mentioned in Table 8. The displacement and surface roughness have been compared with the simulation results which can be highlighted.

The increase of feed rate from $0.05 \mathrm{~mm} / \mathrm{rev}$ to $0.1 \mathrm{~mm} /$ rev can increase the magnitudes of surface roughness in the consecutive experimental steps in Figure 10(a). Likewise the $\mathrm{Ra}$ values are decreased by the minimization of feed rate wherever it can be observed as less. Similarly in Figure 9(b), most of the roughness values are minimum for the lower rotational speed of $2500 \mathrm{rpm}$ which has been predicted already from the main effects of optimization ranked as 3 . The average values of each output parameter can be considered for the precise comparison with the surface roughness in Table 7. Here the lesser value of an average strain of 14.12 and 15.36 and the effective stress of $2149.05 \mathrm{MPa}$ and 2129.52 MPa were obtained due to the occurrence of lesser surface roughness outcomes which was measured by the roughness tester after completion of machining. Based on the average values of SR, it has been observed good as $1 \mu \mathrm{m}$ and $0.64 \mu \mathrm{m}$ for the observation of both HT and non-HT tungsten carbide (WC) for medium and high speed applications.

The stress strain variations are clearly indicated by the different line curves shown in Figure 11. It denotes that the stress strain variation can be abruptly modulated by the influence of machining parameters like speed, tool usage, and the type of milling cutter which was obtained from the optimization outcomes shown in Tables 5 and 6 . In most of the line sampling points along the stress strain curves of Figure 11(b) and 11(d) uniform variation can be obtained for the consecutive results of effective stresses. But in the case of nonheat treated specimen and low rotational speeds, an uneven line curve has been formed as mentioned in Figures 11(a) and 11(c). The understandable stress strain variation can be identified liberally by the observations of WC heat treated specimen with the assistance of higher rotational speeds. The simulation results of various iterative steps can be followed in the simulation tool Deform 3D for utilizing the values of stress effective and displacement at various nodal points of the machining interaction. Here in Figure 12 (a) the displacement value has attained $7.08 \mathrm{~mm}$ as 
TABLE 6: The predicted outputs of SR and relative error by ANN and regression model.

\begin{tabular}{lcccc}
\hline Ex. No & Predicted SR by regression model & Relative error & Predicted SR by ANN & Relative error \\
\hline 1 & 3.34 & -19.28 & 2.56 & 3.01 \\
2.30 \\
2 & 3.34 & -11.52 & 0.35 & 10.16 \\
3 & -0.07 & 118.23 & 0.88 & 2.34 \\
4 & 0.46 & 48.47 & 4.88 & -1.44 \\
6 & 4.37 & 9.09 & 5.34 & 0.21 \\
7 & 4.90 & 8.44 & 1.02 & 1.16 \\
8 & 1.40 & -35.04 & 0.98 & -1.99 \\
\hline
\end{tabular}

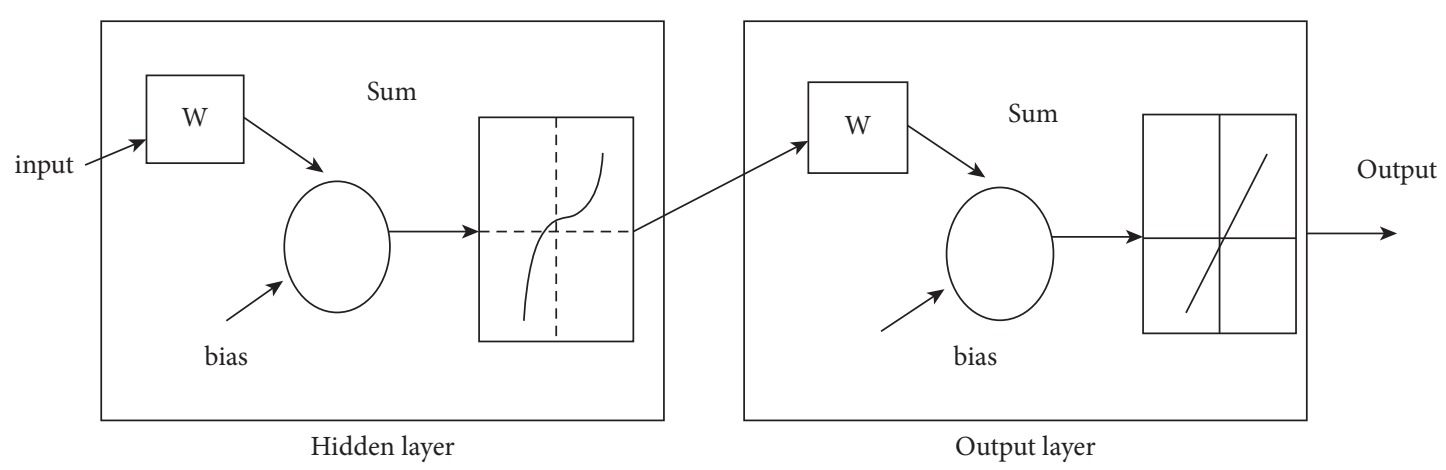

FIgURE 7: ANN hidden layer and output layer structure used for modeling.

TABLe 7: Deform 3D simulation values of effective stress (von Mises) and displacement.

\begin{tabular}{|c|c|c|c|c|}
\hline Step No. & HSS-COLD-2500 & HSS-HOT-3800 & WC-COLD-2500 & WC-HOT-3800 \\
\hline \multicolumn{5}{|c|}{ Effective stress (MPa) } \\
\hline 1 & 1910 & 1810 & 1830 & 2420 \\
\hline 10 & 2190 & 2540 & 2030 & 2430 \\
\hline 20 & 1780 & 2580 & 1990 & 1830 \\
\hline 30 & 2490 & 2660 & 2250 & 2270 \\
\hline 40 & 1940 & 1910 & 1810 & 1480 \\
\hline 50 & 1810 & 2350 & 2300 & 2290 \\
\hline 60 & 2500 & 2260 & 1880 & 2900 \\
\hline 70 & 2300 & 2410 & 2810 & 2530 \\
\hline 80 & 1980 & 2280 & 3050 & 2090 \\
\hline 90 & 1960 & 2220 & 1990 & 1230 \\
\hline 100 & 1820 & 1950 & 1910 & 1720 \\
\hline 110 & 1960 & 2260 & 2560 & 2760 \\
\hline 120 & 1880 & 2040 & 1880 & 2060 \\
\hline 130 & 2050 & 2180 & 2140 & 1880 \\
\hline 140 & 2120 & 2160 & 1510 & 2080 \\
\hline 150 & 1990 & 1580 & 1880 & 1980 \\
\hline 160 & 1960 & 1940 & 2100 & 2520 \\
\hline 170 & 1730 & 2570 & 2010 & 2160 \\
\hline 180 & 1910 & 2390 & 2070 & 2020 \\
\hline 190 & 1730 & 2320 & 2280 & 2150 \\
\hline 200 & 2050 & 1970 & 2430 & 2340 \\
\hline \multicolumn{5}{|c|}{ Displacement (mm) } \\
\hline 1 & 4.24 & 2.16 & 1.33 & 4.46 \\
\hline 10 & 7.96 & 8.11 & 9.14 & 7.92 \\
\hline 20 & 5.3 & 5.09 & 4.93 & 6.01 \\
\hline 30 & 5.53 & 5.95 & 4.47 & 5.88 \\
\hline 40 & 5.08 & 5.58 & 4.47 & 5.68 \\
\hline 50 & 6.87 & 5.39 & 5.33 & 5.73 \\
\hline 60 & 7.05 & 5.9 & 5.75 & 5.73 \\
\hline 70 & 5.84 & 5.24 & 5.76 & 5.73 \\
\hline
\end{tabular}


TABle 7: Continued.

\begin{tabular}{lcccc}
\hline Step No. & HSS-COLD-2500 & HSS-HOT-3800 & WC-COLD-2500 & WC-HOT-3800 \\
\hline 80 & 6.08 & 4.91 & 5.11 & 5.73 \\
90 & 5.9 & 6.83 & 5.12 & 5.73 \\
100 & 5.58 & 5.24 & 5.76 & 5.73 \\
110 & 6.41 & 6.02 & 5.57 & 5.74 \\
120 & 5.8 & 6.04 & 5.51 & 5.74 \\
130 & 5.79 & 5.49 & 5.51 & 5.06 \\
140 & 5.51 & 5.49 & 5.38 & 7.3 \\
150 & 5.25 & 5.4 & 6.03 & 7.29 \\
160 & 7.64 & 6.62 & 6.97 & 7.3 \\
170 & 6 & 5.74 & 5.7 & 7.3 \\
180 & 6.04 & 5.39 & 6.17 & 6.22 \\
190 & 5.5 & 5.9 & 6.99 & 6.43 \\
200 & 5.66 & 6.58 & 6 & \\
\hline
\end{tabular}

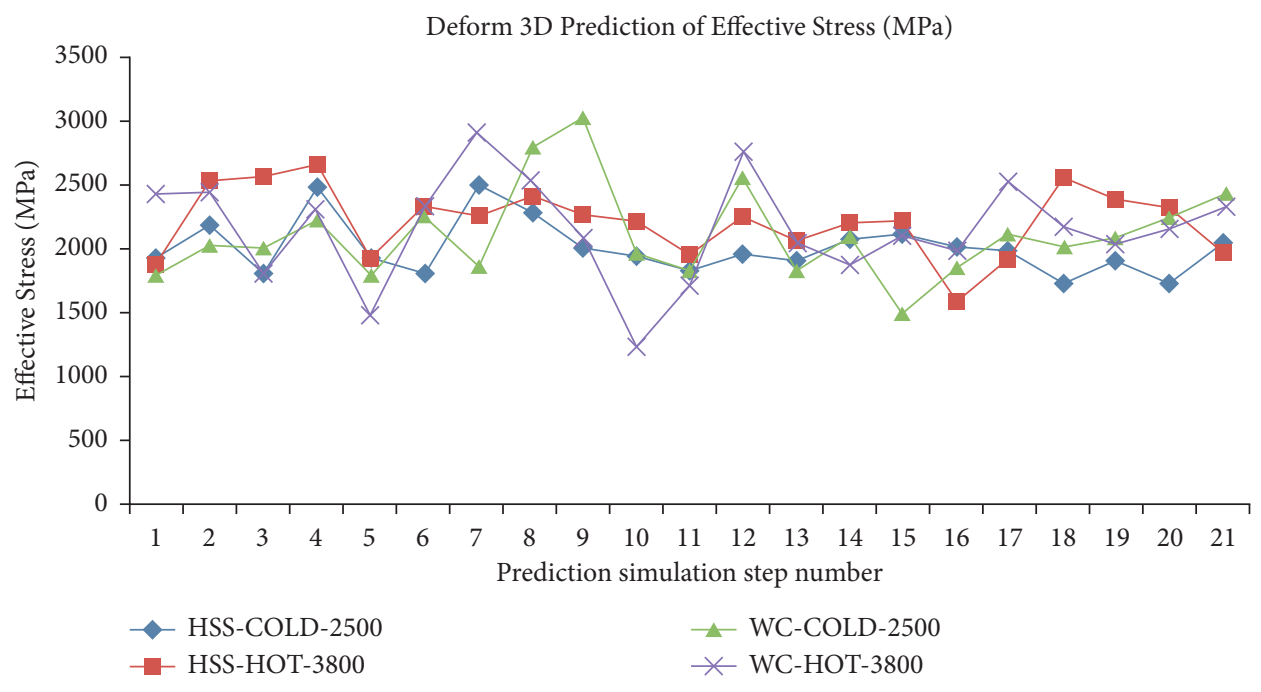

Figure 8: Predicted results of effective stress $(\mathrm{MPa})$ for different step number of Deform 3D.

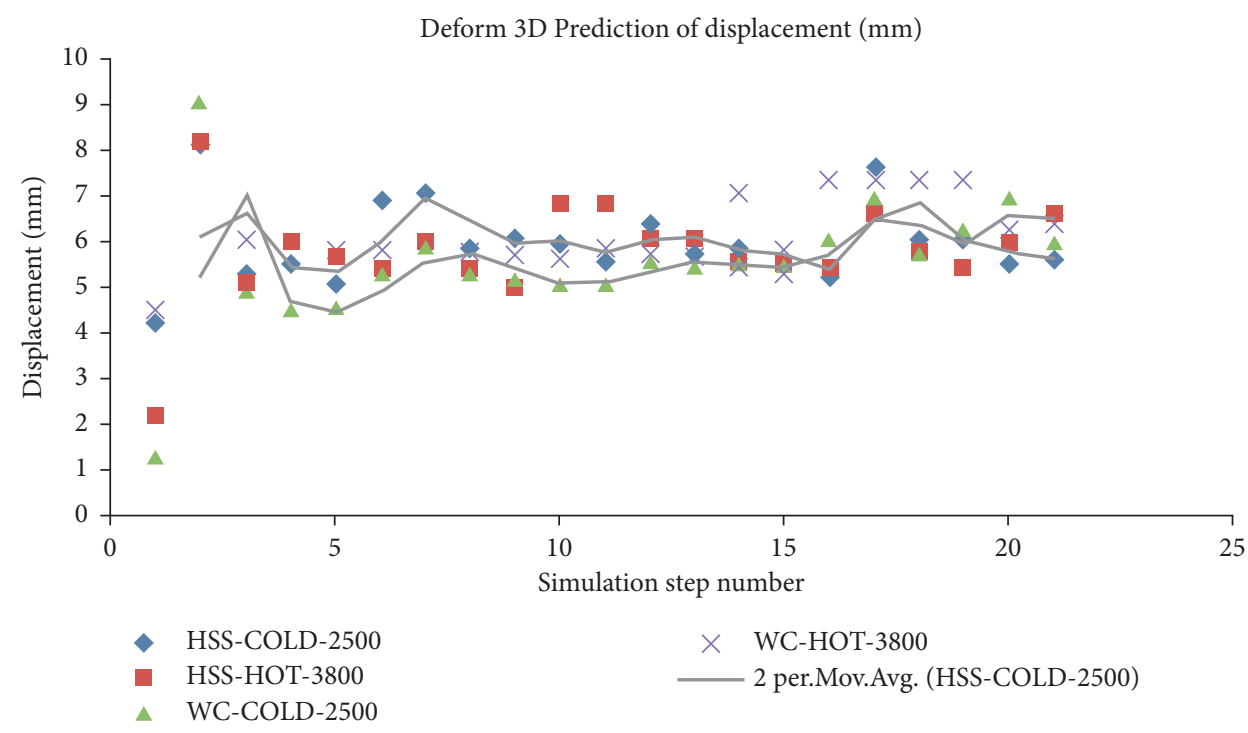

FIGURE 9: Predicted results of displacement ( $\mathrm{mm}$ ) for different step number of Deform 3D. 


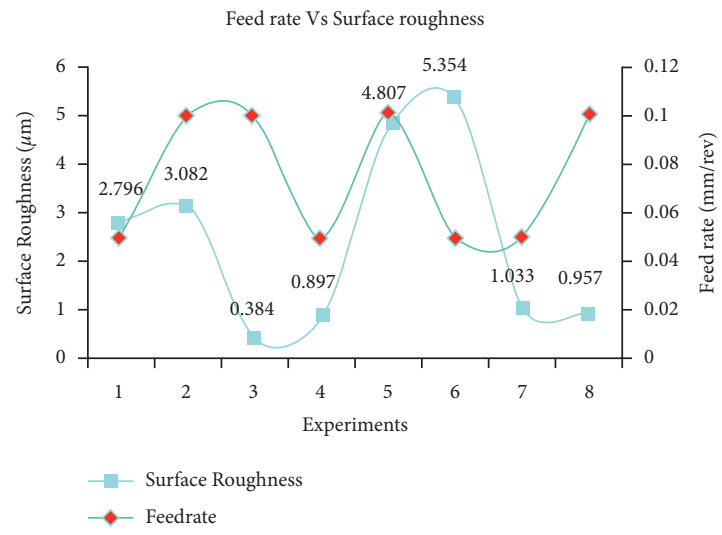

(a)

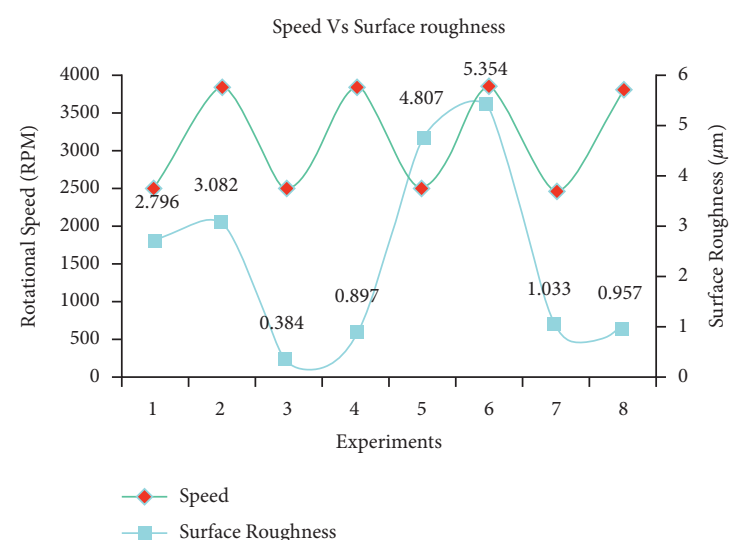

(b)

FIgURE 10: Correspondence of surface roughness with (a) feed rate and (b) rotational speed.

TABLE 8: Comparative average values of simulation outcomes and surface roughness.

\begin{tabular}{lccccc}
\hline Job details & Stress $(\mathrm{MPa})$ & Strain & Principal stress $(\mathrm{MPa})$ & Displacement $(\mathrm{mm})$ & Roughness \\
\hline HSS-COLO-2500 & 2202.86 & 29.76 & 2742.86 & 5.95 & 5.75 \\
HSS-HOT-3800 & 2208.57 & 14.12 & 3161.43 & 5.54 & 2.94 \\
WC-COLD-2500 & 2149.05 & 15.36 & 3022.86 & 3.21 & 1.00 \\
WC-HOT-3800 & 2129.52 & 17.18 & 3203.33 & 0.64 \\
\hline
\end{tabular}

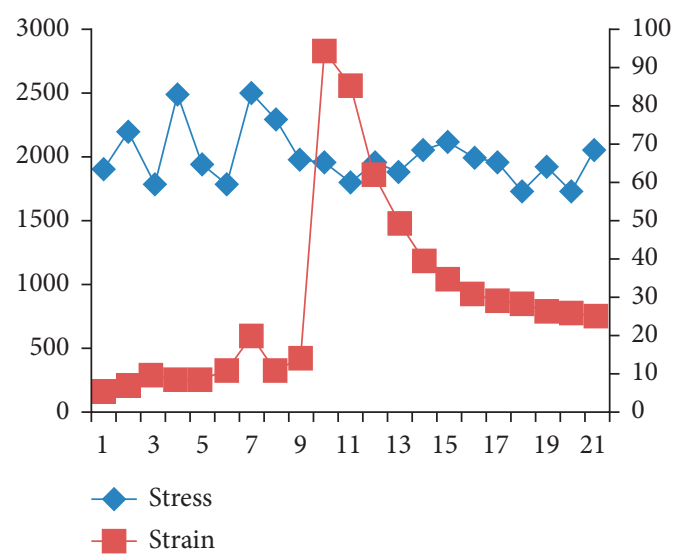

(a)

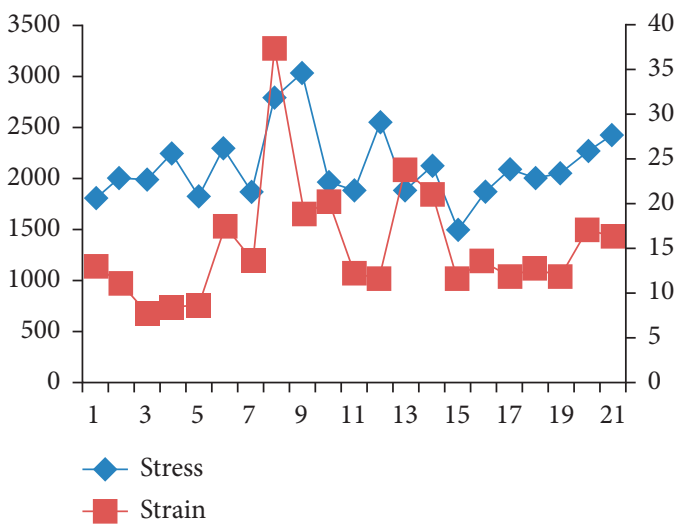

(c)

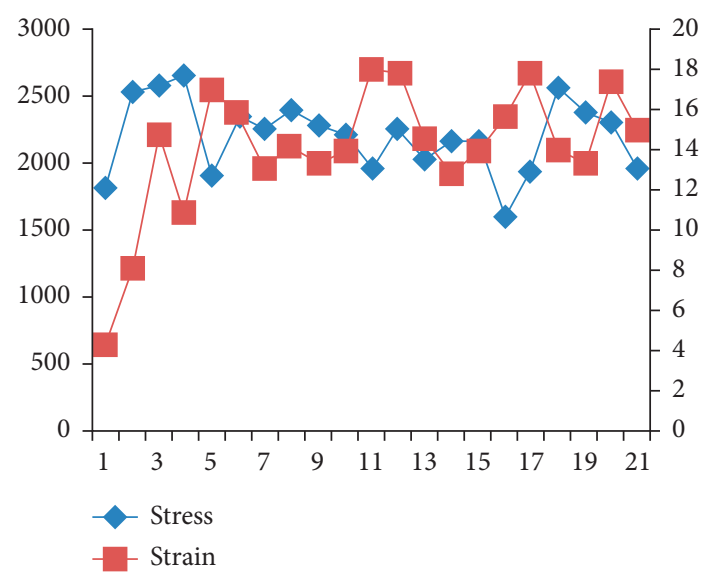

(b)

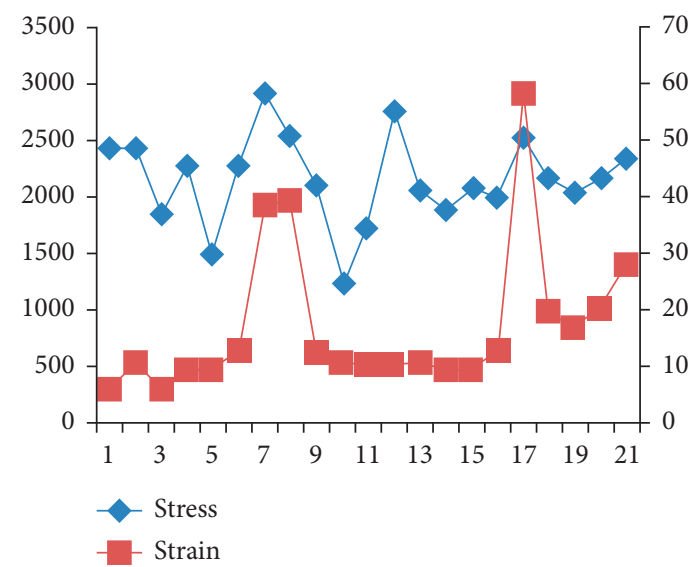

(d)

FIGURE 11: Stress strain curves for cutting conditions of speed 2500, $3800 \mathrm{rpm}$, High Speed Steel (HSS), and tungsten carbide (WC) end milling cutters with heat treated and nonheat treated specimens. 


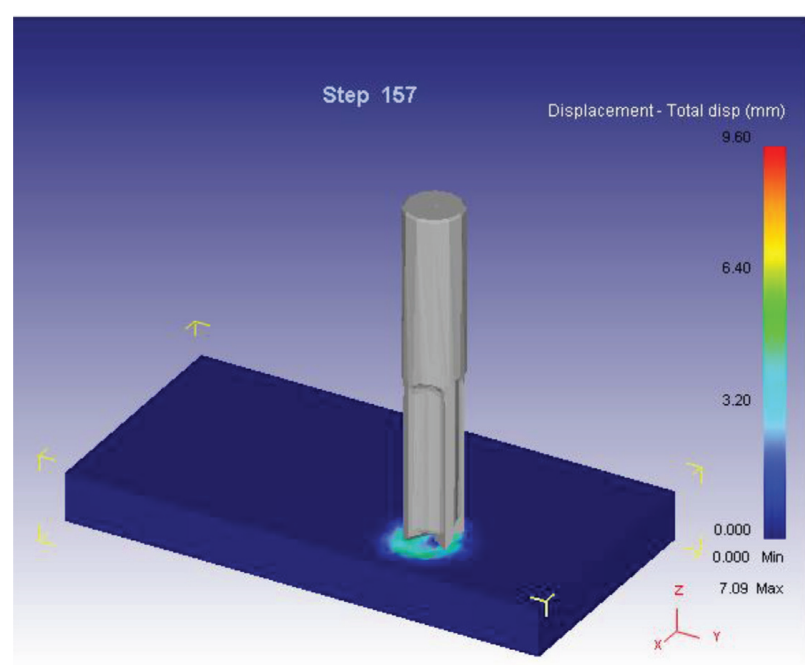

(a)

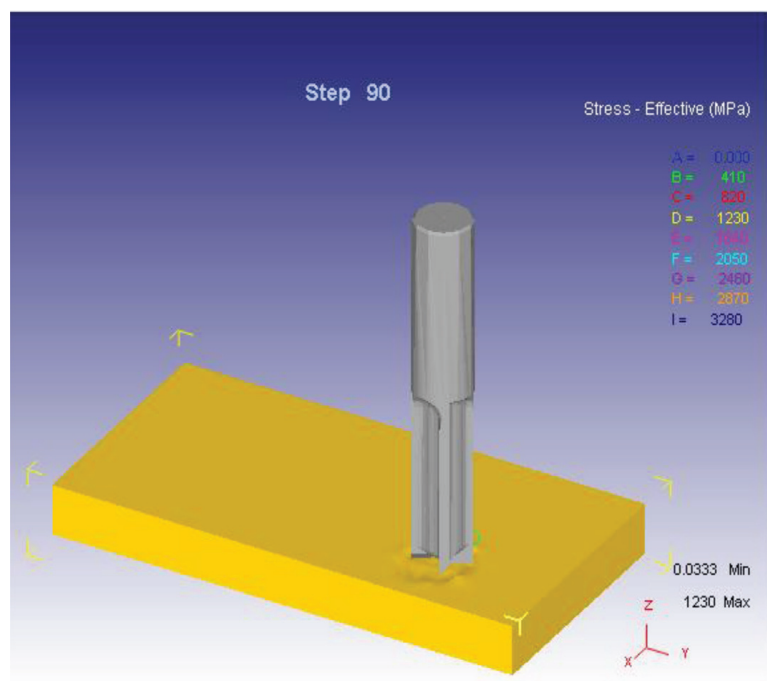

(c)

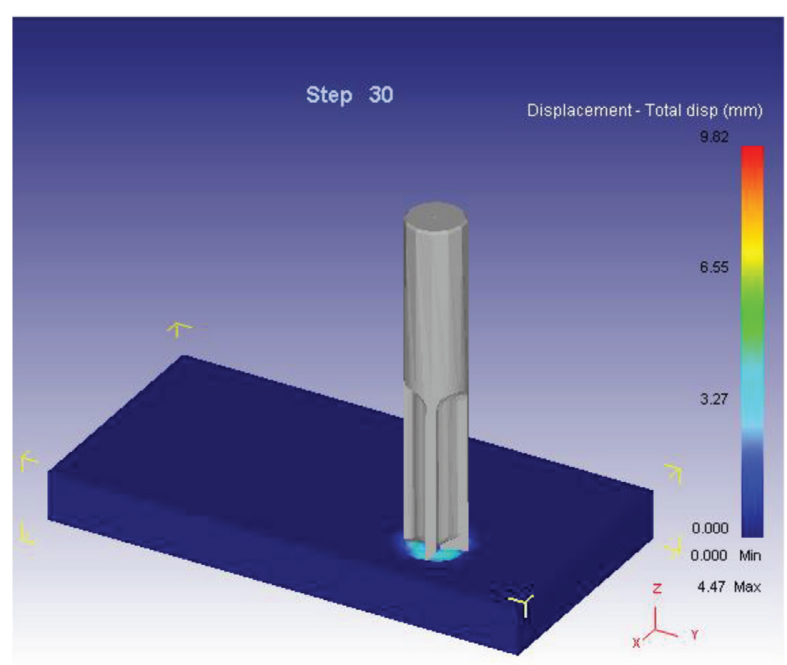

(b)

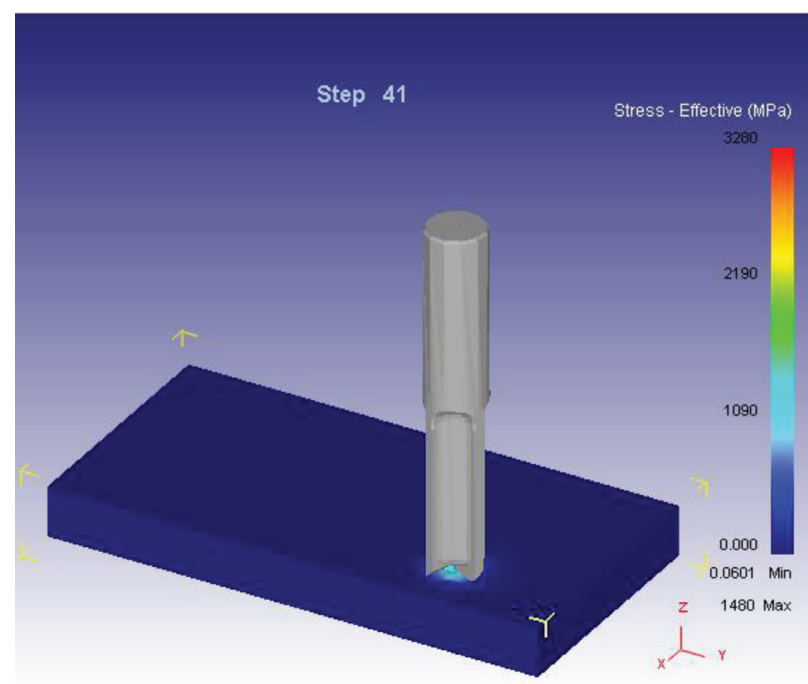

(d)

FIGURE 12: Deform simulation results of (a) higher displacement in step 157 of HSS-non-HT-2500 rpm, (b) lower displacement in step 30 of WC-non-HT-2500 rpm, (c) and (d) lower stress effective in step 90 and 41 of WC-HT-3800 rpm.

maximum at that particular interacted nodal point for the rotational speed of $2500 \mathrm{rpm}$ machined with HSS nonheat treated milling cutter.

Similarly, the lower displacement value has been attained for the same rotational speed as $4.47 \mathrm{~mm}$ as maximum at that iterative step of 41 as shown in Figure 12(b). In addition, the effective or von Mises stress has been found such that it has been decreased from $1480 \mathrm{MPa}$ to $1230 \mathrm{MPa}$ using WC milling cutter for the speed of $3800 \mathrm{rpm}$ as mentioned in Figures 12 (c) and $12(\mathrm{~d})$. In most of the simulation results stress effective ranges are from $1500 \mathrm{MPa}$ to $2000 \mathrm{MPa}$ for the higher rotational speed of $3800 \mathrm{rpm}$.

\section{Conclusion}

The contribution of alloying elements in the Al6061 alloys is used elaborately for elevating the mechanical properties.
Besides, the heat treatment is an added advantage of strengthening the structure of the Al6061 alloy specimen. The machinability has been improved by this dual heat treatment (DHT) method, which has been observed from the outcome of surface roughness average of $1.78975 \mu \mathrm{m}$ as a minimum. The application of this DHT process has achieved a $41 \%$ improvement in roughness. The optimized surface roughness results clearly explained that the tool and the workpiece type are the primary and secondary influencing Ra's parameters. The tool deviations made a separate differentiation among the surface quality of the machined slots. A similar experimental value has been obtained for the predicted values. This can be confirmed through the ANN and GA techniques. The separate classifications of Deform $3 \mathrm{D}$ simulation outcomes helped predict the tool's interactive performances over workpieces for the specified cutting conditions. The WC cutting tool's simulation results machined with the heat treated specimen for the higher 
rotational speed were satisfied with the experiment's good roughness outcome. Thus the experimental and simulation data are somehow interrelated coherently with each other.

\section{Abbreviations}

$\begin{array}{ll}\text { Ra, SR: } & \text { Surface roughness in } \mu \mathrm{m} \\ \text { GA: } & \text { Genetic algorithm } \\ \text { ANN: } & \text { Artificial Neural Network } \\ \text { N: } & \text { Rotational speed } n \mathrm{rpm} \\ \mathrm{d}: & \text { Depth of cut in } \mathrm{mm} \\ \mathrm{f}: & \text { Feed rate in } \mathrm{mm} / \mathrm{rev} \\ \text { WC: } & \text { Tungsten carbide }(\mathrm{WC}) \\ \text { HSS: } & \text { High Speed Steel } \\ \text { DHT: } & \text { Dual heat treatment. }\end{array}$

\section{Data Availability}

The data used to support the findings of this study are included in the article. Should further data or information be required, these are available from the corresponding author upon request.

\section{Conflicts of Interest}

The authors declare that there are no conflicts of interest regarding the publication of this paper.

\section{Acknowledgments}

The authors appreciate the technical assistance to complete this experimental work from Department of Mechanical Engineering, Saveetha School of Engineering, Saveetha Institute of Medical and Technical Sciences, Chennai. The authors appreciate the technical assistance to complete this experimental work. Authors declared that no funding was received for this research and publication. It was performed as a part of the Employment Wollega University, Ethiopia.

\section{References}

[1] F. Kahraman and A. Sagbas, "An investigation of the effect of heat treatment on surface roughness in machining by using statistical analysis," Iranian Journal of Science and Technology Transaction B-Engineering, vol. 34, no. B5, pp. 591-595, 2010.

[2] S. Cetinkaya and A. Kacal, "Investigation of the heat treatment effect in milling of K390 powder metallurgical steel," Kovové materiály, vol. 52, pp. 209-218, 2014.

[3] M. Azadi Moghaddam and F. Kolahan, "Application of orthogonal array technique and particle swarm optimization approach in surface roughness modification when face milling AISI1045 steel parts," Journal of Industrial Engineering International, vol. 12, no. 2, pp. 199-209, 2016.

[4] İ. Ucun, K. Aslantas, and F. Bedir, "Finite element modeling of micro-milling: numerical simulation and experimental validation," Machining Science and Technology, vol. 20, no. 1, pp. 148-172, 2016.

[5] V. Arumugaprabu, T. J. Ko, S. T. Kumaran et al., "Performance of surface-textured end-mill insert on AISI 1045 steel," Materials and Manufacturing Processes, vol. 34, no. 1, pp. 18-29, 2018.
[6] S. Xiulin, Z. Shiguang, G. Yang, and C. Bin, "3-D finite element simulation analysis of milling titanium alloy using different cutting edge radius," in Proceedings of the 2015 Sixth International Conference on Intelligent Systems Design and Engineering Applications (ISDEA), Guiyang, Guizhou, China, 2015.

[7] G. K. Hedberg and Y. C. Shin, "Laser assisted milling of Ti$6 \mathrm{Al}-4 \mathrm{~V}$ ELI with the analysis of surface integrity and its economics," Lasers in Manufacturing and Materials Processing, vol. 2, no. 3, pp. 164-185, 2015.

[8] D. Y. Pimenov Pimenov, V. I. Guzeev, T. Mikolajczyk, and K. Patra, "A study of the influence of processing parameters and tool wear on elastic displacements of the technological system under face milling," International Journal of Advanced Manufacturing Technology, vol. 92, no. 9-12, pp. 4473-4486, 2017.

[9] N. Gorain, M. GulabWalunj, M. Kumar Soni, and B. Ravi Kumar, "Effect of continuous annealing process on various structure parameters of martensite of dual-phase steels," Archives of Civil and Mechanical Engineering, vol. 20, no. 29, 2020.

[10] X. Chuangwen, X. Ting, Y. Xiangbin, Z. Jilin, L. Wenl, and L. Huaiyuan, "Experimental tests and empirical models of the cutting force and surface roughness when cutting $1 \mathrm{Cr} 13$ martensitic stainless steel with a coated carbide tool," Advances in Mechanical Engineering, vol. 8, no. 10, Article ID 168781401667375, 2016.

[11] R. K. Beemaraj, M. S. Chandra Sekar, and V. Vijayan, "Computer vision measurement and optimization of surface roughness using soft computing approaches," Transactions of the Institute of Measurement and Control, vol. 42, no. 13, pp. 2475-2481, 2020.

[12] M. Kvietkova, M. Gaparik, and M. Gaff, "Effect of thermal treatment on surface quality of beech wood after plane milling," Bio Resources, vol. 10, no. 3, pp. 4226-4238, 2015.

[13] B. Bloul, A. Bourdim, S. Hamou, and M. Bourdim, "Geometric analysis of the influence of perpendicularity of a spindle axis of the milling machine on the surface quality," Advances in Mechanical Engineering, vol. 9, no. 4, Article ID $168781401770083,2017$.

[14] J. Moritz, A. Seidel, M. Kopper et al., "Hybrid manufacturing of titanium Ti-6Al-4V combining laser metal deposition and cryogenic milling," International Journal of Advanced Manufacturing Technology, vol. 107, no. 7-8, pp. 2995-3009, 2020.

[15] P. Feng, S. A. Abbasi, Y. Ma, J. Zhang, D. Yu, and Z. Wu, "Influence of microstructure and hardness on machinability of heat-treated titanium alloy Ti-6Al-4V in end milling with polycrystalline diamond tools," International Journal of Advanced Manufacturing Technology, vol. 86, pp. 1393-1405, 2016.

[16] C. Zhang, S. Zhang, X. Yan, and Q. Zhang, "Effects of internal cooling channel structures on cutting forces and tool life in side milling of $\mathrm{H} 13$ steel under cryogenic minimum quantity lubrication condition," International Journal of Advanced Manufacturing Technology, vol. 83, no. 5-8, pp. 975-984, 2016.

[17] X. Chen, S. J. Wang, S. To et al., "Effect of cutting parameters on heat generation in ultra-precision milling of aluminum alloy 6061," International Journal of Advanced Manufacturing Technology, vol. 80, pp. 1265-1275, 2015.

[18] A. Bovas Herbert Bejaxhin and G. Paulraj, "Effect of optimised cutting constraints by AlCrN/epoxy coated components on surface roughness in $\mathrm{CNC}$ milling," International 
Journal of Rapid Manufacturing, vol. 8, no. 4, pp. 397-417, 2019.

[19] Y. Houchuan, C. Zhitong, and Z. ZiTong, "Influence of cutting speed and tool wear on the surface integrity of the titanium alloy Ti-1023 during milling," International Journal of Advanced Manufacturing Technology, vol. 78, no. 5-8, pp. 1113-1126, 2015.

[20] X.-C. Wang, C.-C. Wang, C.-Y. Wang, and F.-H. Sun, "Approach for polishing diamond coated complicated cutting tool: abrasive flow machining (AFM)," Chinese Journal of Mechanical Engineering, vol. 31, no. 1, 2018.

[21] S. S. Warsi, S. H. I. Jaffery, and R. Ahmad, "Development and analysis of energy consumption map for high-speed machining of Al 6061-T6 alloy," International Journal of Advanced Manufacturing Technology, vol. 96, pp. 91-102, 2018.

[22] Ş. Bayraktar and A. P. Hekimoğlu, "Effect of zinc content and cutting tool coating on the machinability of the Al-(5-35) $\mathrm{Zn}$ alloys," Metals and Materials International, vol. 26, pp. 477490, 2020.

[23] S. S. Warsi, T. Zahid, H. Elahi et al., "Sustainability-based analysis of conventional to high-speed machining of Al 6061T6 alloy," Applied Sciences, vol. 11, no. 19, p. 9032, 2021.

[24] B. Aldwell, E. Kelly, R. Wall, A. Amaldi, G. O’Donnell, and R. Lupoi, "Machinability of Al 6061 deposited with cold spray additive manufacturing," Journal of Thermal Spray Technology, vol. 26, no. 7, pp. 1573-1584, 2017.

[25] K. Jarosz, P. Löschner, P. Niesłony, and K. Grzegorz, “Optimization of CNC face milling process of Al-6061-T6 aluminum alloy," Journal of Machine Engineering, vol. 17, pp. 69-77, 2017. 